\title{
Disinformation online: potential legal and regulatory ramifications to the right to free elections - policy position paper
}

\author{
Krisztina Rozgonyi \\ University of Vienna, 1090 Vienna, Währingerstrasse 29 \\ krisztina.rozgonyi@univie.ac.at
}

\begin{abstract}
This paper provides an overview on the implications of digital information disorder to exercise the right to free elections. It suggests a need for public scrutiny and calls for action on the revision of rules on political advertising, on enhanced accountability of internet intermediaries, on strengthening quality journalism and empowerment of voters towards a critical evaluation of electoral communication. Furthermore, it considers the potential role and involvement of national regulators and of the judiciary in law enforcement and regulation.
\end{abstract}

\section{Keywords}

Information disorder - the right to free elections - accountability of online platform providers'

How to cite this book chapter:

Rozgonyi, K. 2020. Disinformation online: potential legal and regulatory ramifications to the right to free elections - policy position paper. In: Loizides, F., Winckler, M., Chatterjee, U., Abdelnour-Nocera, J. and Parmaxi, A. (eds.) Human Computer Interaction and Emerging Technologies: Adjunct Proceedings from the INTERACT 2019 Workshops. Pp. 57-66. Cardiff: Cardiff University Press. DOI: https://doi. org/10.18573/book3.g. License: CC-BY 4.0. 


\section{Information disorder and its (potential) impact on elections}

The internet has, to a large extent, changed political campaigning. Major political events in 2016 in the United Kingdom and the United States of America, namely the Brexit referendum and the presidential election respectively, pointed to several potentially critical defects in the regulatory regimes governing political campaigning online. The enforcement of rules and regulations on paid advertising was limited; voters' personal data were collected and processed for election purposes without their consent and in lack of legal entitlement; political communication was channeled to unregulated social media platforms without safeguards in place on fair media coverage. Moreover, digital content production and dissemination on social media exposed citizens to disinformation, including propaganda-driven falsified news. These implications fundamentally challenged the established institutions and principles of regulation of election communications [1] and interfered with democracy in distorting public and informed discourse of the electorate. The erosion of the watchdog-function of traditional media and a general loss in trust in such media accompanied this process.

The combined effects of these changes led to the stage of information disorder [2], making possible the spread of false and/or harmful information on an unprecedented scale without effective control or countering. This was reached as a consequent change in media consumption practices with social media becoming one of the primary sources of news across the world [3]. Social media platform operators, a type of internet intermediary, ${ }^{1}$ give access to and host content, facilitating its creation and sharing among their virtual networks and communities. Such platform operators acquired control over the flow, availability, findability and accessibility of information and other content online whereby users "discover" content rather than search for specific information. By now, a serious shift in the influence of internet-based channels of electoral communication has reached a tipping point in terms of immediacy and power [4] and dominance [5]. Citizens thus depend to a large extent on

${ }^{1}$ The term 'internet intermediaries' refers to the operators of online media platforms, of search engines, social networks and app stores [15]. According to the Council of Europe's Recommendation CM/Rec(2018)2 on the roles and responsibilities of internet intermediaries, these players facilitate interactions on the internet between natural and legal persons by offering and performing a variety of functions and services. Some connect users to the internet, enable the processing of information and data, or host webbased services, including for user-generated content. Others aggregate information and enable searches; they give access to, host and index content and services designed and/or operated by third parties. Some facilitate the sale of goods and services, including audio-visual services, and enable other commercial transactions, including payments. 
the social platforms' content moderation and amplification policies, and the algorithms designed for maximum engagement and exploitation of network effects. It is this unexplored context within which the deeply rooted, but newly re-loaded nature of human communication plays out. People are more likely to share untrue news especially if they were to trigger emotions. There is an agreement in the academic community that the spread of misinformation was not to be blamed on algorithms [6] or robots, but on humans who were eager to spread it [7]. And this vulnerability served the aims of many acting with the intent of harmdoing.

Governments, the military and political parties engaged cyber troops committed to manipulating public opinion over social media benefitting such communicative patterns. Organized interventions emerged first in 2010 and affected at least 30 countries by now [8-9]. Social media platforms and search engines [10] were the main targets of manipulations potentially skewing the election results in favor of a particular political option. Meanwhile, these incidents were only partially countered by the media. News consumption via social media cut out to a large extent journalism from its established gatekeeper position supported by editorial practices, ethical obligations and regulatory frameworks. Also, policymakers, governments and civil society alike had to face the reality of their limited potential enforcing existing laws on electoral campaigns and regulations of political advertising on the internet across jurisdictions. This environment potentially undermines the exercise of the right to free elections and creates considerable risks to the functioning of a democratic system.

\section{The positive obligations of the State ensuring the right to free elections: what role for public scrutiny and which measures to apply?}

Within Europe, under the Convention for the Protection of Human Rights and Fundamental Freedoms as interpreted by the European Court of Human Rights, States have an obligation to secure the right to free elections enshrined in Article 3 of Protocol No. 1 to the Convention. The right to free elections incorporates the right to vote and the right to stand for election. Moreover, it also entails a positive obligation of the States to ensure conditions under which people can freely form and express their opinions and choose their representatives which is of utmost relevance to the (un)disrupted communicative context of elections. Furthermore, the right to freedom of expression (Article 10) and of election are intertwined as reaffirmed by the Court in stating, that "free elections and freedom of expression, particularly freedom of political debate, together form the bedrock of any democratic system". ${ }^{2}$ We should then consider

${ }^{2}$ Bowman v the United Kingdom App. no. 24839/94 (ECtHR, 19 February 1998), para 42. 
what necessary and possible steps are to be taken in safeguarding a democratic electorate in the age of information disorder.

\subsection{Legislative interventions by the State and regulatory oversight}

After a decade of liability by 'safe harbors' ${ }^{3}$ provided to intermediaries all around the world, the policy discourse shifted to 'intermediary responsibility' along with an overall move towards incentivizing intermediaries private ordering online [11]. There is a wide consensus on the limits of such responsibility: platform providers should not be responsible for third-party content but for administering their platform rules [12] thus securing a safe and undistorted sphere to public debate. This duty would entail inter alia protection of users' personal data and of privacy and provision of non-disturbing channels to receive and impart information. Depending on national contexts this is to trigger legislative and regulatory interventions and new approaches to public scrutiny. The revision of rules and regulations on political advertising is of priority here. The equal and fair access of political parties to campaign through social media requires updating of broadcasting quotas and the introduction of new measures covering internetbased media. Campaign spending limits and sources of funding are to be effectively enforced with the broadening scope of communication channels covered by the relevant legislation and ensuring the monitoring capacities of national election bodies. Backstop options, such as immediate and effective intervention by public authorities, and the judiciary in case of breach of the law are of vital importance. The newly adopted French Bill on Combating the manipulation of information ${ }^{4}$ is the first legislative example in this direction.

Protection of personal data of the electorate from misuse of microtargeting is the next area of public action. The fine-tuning of applicable laws according to national context should focus on enforceability. Within European Union member states the General Data Protection Regulation (GDPR) creates obligations on social media companies as joint data controllers to process personal data lawfully, fairly and transparently. However, the monitoring and enforcement competences of national data protection authorities needs further legislative backup and robust capacity enhancement.

The dissemination of disinformation and propaganda on online media platforms needs careful and narrowly tailored legislative design accompanied

${ }^{3}$ In the US laws such as Section 512 of the US Digital Millennium Copyright Act (DMCA) and Section 230 of the US Communications Decency Act (CDA Section 230), while in the European Union (EU) the E-Commerce Directive were to ensure exemptions to intermediaries from liability to third party user generated content.

${ }^{4}$ Loi du 29 juillet 1881 sur la liberté de la presse. 
with vigorous regulatory oversight. Any laws adopted need to comply with international, European and national standards on freedom of expression which severely limit intervention options. Moreover, tempting solutions of the 'privatization of censorship' with general content monitoring obligations put on platform providers or outsourcing law enforcement to those operators, should not to be followed. The first law in force in Germany against dissemination of hate speech, of propaganda and of terrorist content ${ }^{5}$ since 2018 that has left enforcement to social networks without in-depth public or judiciary control needs to be critically evaluated and its impact assessed. The newly published proposals on national legislative actions in the UK (UK Governments' Online Harms White Paper - April 2019) ${ }^{6}$ or in in France (Interim Government Report May 2019) ${ }^{7}$ should reflect on such assessments avoiding the incorporation of rules with detrimental effects.

\subsection{Responsibility of platform providers and self-regulation}

Online media platform providers came under various political and legislative pressure since the 2016 US and UK election (referendum) incidents. They have had to commit themselves to a new era of public enquiry. At the European Parliamentary hearing Mark Zuckerberg also admitted the need for regulation $^{8}$. Hatred online and disrupted election procedures topped the political agenda, so online media platforms have adhered to selfregulatory measures

${ }^{5}$ Germany adopted in 2017 the Network Enforcement Act (Netzdurchsetzunggesetz, NetzDG) on setting reporting and removal requirements on social networks with regards to unlawful content. France passed a new law (LOI n ${ }^{\circ}$ 2018-1202 du 22 décembre 2018 relative à la lutte contre la manipulation de l'information) at the end of 2018 on removal of "fake news" during election campaigns.

${ }^{6}$ See at https://www.gov.uk/government/consultations/online-harms-white -paper.

${ }^{7}$ Creating a French framework to make social media platforms more accountable: Acting in France with a European visionInterim mission report "Regulation of social networks - Facebook experiment" Submitted to the French Secretary of State for Digital Affairs May 2019.

8 "I don't think the question is whether or not there should be regulation. I think the question is what is the right regulation ... The important thing is to get this right," (Mark Zuckerberg at the EP hearing on 22 May 2018, see at http://www.europarl.europa.eu/news/en/press-room/20180522IPR04024 /mark-zuckerberg-meeting-with-european-parliament-leaderstoday). 
at least within the EU. First on combatting hate speech online ${ }^{9}$ and next on countering election disorders. The Code of Practice on Disinformation ${ }^{10}$ was to address legitimate calls to accountability in terms of enhancing transparency of spending for political advertising and shifting revenue streams away from sources of propaganda and disinformation.

This self-regulatory effort is in place since September 2018 and was to prevent interventions during the May 2019 European Parliamentary elections. The commitments made by the signatories focused on advert placements and avoiding the promotion of websites or adverts that spread disinformation; on clearly distinguished management of political and issue-based advertising from editorial content including transparency on sponsored content; on service integrity tackling fake accounts and improving transparency around the use of bots; and generally empowering users by making it easier to find trustworthy and diverse sources of news. In order to monitor progress, the European Commission has received monthly reports ${ }^{11}$ on actions taken towards implementation of the commitments on electoral integrity. The reports indeed showcased several efforts made by platform providers on preventing election intrusions, and generally reducing disinformation. Yet, the true impact of such actions needs further analyses and independent assessment, especially with regards to potential chilling effects on communication. ${ }^{12}$ Also, critics expressed concern about the lack of indicators while the Code was adopted; ${ }^{13}$ measurable results need to be re-addressed for truthful evaluation of the self-regulatory regime.

9 To prevent and counter the spread of illegal hate speech online, in May 2016, the Commission agreed with Facebook, Microsoft, Twitter and YouTube a "Code of conduct on countering illegal hate speech online". See at https://ec.europa.eu /info/policies/justice-and-fundamental-rights/combatting-discrimination /racism-and-xenophobia/countering-illegal-hate-speech-online_en.

10 The Code of Practice on Disinformation as enshrined by the Communication from the Commission on tackling online disinformation: a European Approach. Brussels, 26.4.2018 COM(2018) 236 final. Signatories include some of the largest platform providers, such as Facebook, Google, Twitter, and Mozilla.

${ }^{11}$ See at https://ec.europa.eu/digital-single-market/en/news/fourth-intermediate -results-eu-code-practice-against-disinformation.

${ }^{12}$ It remained unclear on what accounts and according which standards content had been identified as "disinformation", nor due process guarantees were adopted ensuring appeal against such decisions.

13 See the comments of the Sounding Board on the Code of Practice stressing that the Code "contains no common approach, no clear and meaningful commitments, no measurable objectives or KPIs, hence no possibility to monitor process, and no compliance or enforcement tool: it is by no means self-regulation, and therefore the Platforms, despite their efforts, have 
Furthermore, meaningful civil society initiatives emerged such as the Global Disinformation Index to reduce disinformation. with a focus on the ad-tech industry ${ }^{14}$ or the FactCheckEU of 19 European media outlets from 13 countries. ${ }^{15}$ The contribution of such schemes to the policy debate needs to be assessed. The structural and de facto limitations of self-regulation as an effective tool to protect citizens' and of human rights should additionally inform the debate. The well-founded arguments of policy scholars on the need for critical study of self-(solo-)regulatory mechanisms [13] as well as detailed election media monitoring data analyse ${ }^{16}$ are to guide such efforts.

Arguably the positive obligations of the State in ensuring the enjoyment of the right to free elections implies the enforcement of obligations imposed on platforms should not be left at the discretion of their providers. The representation of the public interest necessitates active involvement of public actors, such as regulators and the judiciary along with civic engagement. The securement of human rights, the balancing of freedom of expression with harm assessment needs to imply checks and balances fundamental in democratic contexts.

\section{Further discussion}

However, the extent and the manner of public interest involvement are neither straightforward, nor tested. There are no best or worst cases to be consulted. Previous regulatory models and organizational arrangements are as much restricting as they are enabling the creation of future scenarios. It is therefore the challenge for policy-makers, to academia and to civil society to cooperate and co-create an enabling environment safeguarding the basic tenets of democracy. Lessons are to be learned with an interdisciplinary approach and across sectors on the necessary skills and competencies [14], to methodological as well as logistical matters to such involvement. Collaborative and flexible

not delivered a Code of Practice." at https://ec.europa.eu/newsroom/dae /document.cfm?doc_id=54456.

${ }^{14}$ See at https://disinformationindex.org/wp-content/uploads/2019/05/GDI _Report_Screen_AW2.pdf.

15 See at https://factcheckeu.info/en/.

16 The upcoming elections in Ukraine in July 2019 could serve as a testbed for such research. Since the 2019 Presidential elections were already subject to high level international observations (see e.g. Council of Europe reports at https://www.coe.int/en/web/kyiv/-/which-candidates-do-ukrainian-media -favour-results-of-media-monitoring) with transparent methodological foundations (seeathttp://www.cje.org.ua/sites/default/files/library/FIN_ENG _Media\%20Monitoring\%20Methodology_Ukraine.pdf) it is to be expected that the next electoral process would also provide in-depth data for independent analyses. 
intervention tools are to be developed with an overall participatory attitude. The globality, the pace and the rapidity of the environment under oversight requests responsible and responsive collaboration of all stakeholders involved.

\section{References}

1. Tambini, D.: Social Media Power and Election Legitimacy. In D. Tambini \& M. Moore, Digital dominance: the power of Google, Amazon, Facebook, and Apple (pp. 265-293). Oxford University Press, New York (2018).

2. Wardle, C., \& Derakhshan, H.: Information disorder: Toward an interdisciplinary framework for research and policy making (No. REF. 162317GBR). Council of Europe, http://edoc.coe.int/en/media/7495 -information-disorder-toward-an-interdisciplinary-framework-for -research-and-policy-making.html, Strasbourg (2017).

3. Reuters Institute: Digital News Report 2019, https://reutersinstitute.politics .ox.ac.uk/sites/default/files/2019-06/DNR_2019_FINAL_0.pdf (2019).

4. Plaizier, C.: Micro-targeting Consent - A human rights perspective on paid political advertising on social media. University of Amsterdam, Amsterdam (2018).

5. Tambini, D.: Internet and electoral campaigns - Study on the use of internet in electoral campaigns - Council of Europe study, DGI(2017)11. Council of Europe Committee of experts on media pluralism and transparency of media ownership (MSI-MED), http://edoc.coe.int/en/internet/7614 -internet-and-electoral-campaigns-study-on-the-use-of-internet-in -electoral-campaigns.html, Strasbourg (2017).

6. Lazer, D. M. J., Baum, M. A., Benkler, Y., Berinsky, A. J., Greenhill, K. M., Menczer, F., ... Zittrain, J. L.: The science of fake news. Science, 359(6380), 1094-1096 (2018).

7. Vosoughi, S., Roy, D., \& Aral, S.: The spread of true and false news online. Science, 359(6380), 1146-1151 (2018).

8. Bradshaw, S., \& Howard, P. N.: Troops, Trolls and Troublemakers: A Global Inventory of Organized Social Media Manipulation (No. Working paper no. 2017.12). Computational Propaganda Research Project by the Oxford Internet Institute, http://comprop.oii.ox.ac.uk/wp-content/uploads/sites /89/2017/07/Troops-Trolls-and-Troublemakers.pdf, Oxford (2017).

9. Freedom House: Freedom on the Net 2018: The Rise of Digital Authoritarianism, https://freedomhouse.org/report/freedom-net/freedom-net-2018 /rise-digital-authoritarianism (2018).

10. Epstein, R., \& Robertson, R. E.: The search engine manipulation effect (SEME) and its possible impact on the outcomes of elections. Proceedings of the National Academy of Sciences, 112(33), E4512-E4521 (2015). 
11. Frosio, G. F.: Why keep a dog and bark yourself? From intermediary liability to responsibility. International Journal of Law and Information Technology, 26(1), 1-33. (2017).

12. Bayer, J., Bitiukova, N., Bárd, P., Szakács, J., Alemanno, A., \& Uszkiewicz, E.: Disinformation and propaganda - impact on the functioning of the rule of law in the EU and its Member States, European Parliament Policy Department for Citizens' Rights and Constitutional Affairs, Brussels (2019).

13. Milosavljević, M., \& Micova, S. B.: Banning, Blocking and Boosting: Twitter's Solo-Regulation of Expression. Medijske Studije = Media Studies; 7(13), 43-58, Zagreb (2016).

14. Rozgonyi, K.: A new model for media regulation. Intermedia, 46(1), 18-23, http://iicom.org/images/iic/intermedia/april-2018/im-apr2018-vol46 -iss01_media-regulation.pdf (2018).

15. van der Noll, R., Helberger, N., \& Kleinen-von Königslöw, K.: Regulating the new information intermediaries as gatekeepers of information diversity. Info, 17(6), 50-71 (2015). 